\title{
Being a homosexual to bisexual: Overlapping sexual risks among men who have sex with men as well as women in South Asian countries
}

\author{
S.K. Singh ${ }^{1}$, Deepanjali Vishwakarma ${ }^{2}$, A. Rahman ${ }^{3}$, Santosh Kumar Sharma ${ }^{4}$, S. Khan ${ }^{5}$, Alankar Malviya ${ }^{6}$, Bhawana Sharma $^{7}{\text { and Tshering }{ }^{8}}^{8}$ \\ ${ }^{1}$ International Institute for Population Sciences, Department of Mathematical Demography and Statistics, Mumbai, India \\ ${ }^{2}$ International Institute for population Sciences, Mumbai, Maharashtra, India \\ ${ }^{3}$ UNAIDS, Kathmandu, Nepal \\ ${ }^{4}$ National STI and HIV/AIDS Control programme, Department of Public health, Ministry of Health, Royal Government Bhutan \\ ${ }^{5}$ Ministry of Health, Bangladesh \\ ${ }^{6}$ UNAIDS, Bangladesh
}

\begin{abstract}
Background: Heterosexual relations among bisexual MSM engender spectrum of vulnerabilities for MSM as well as their partners. Socio-cultural pressure to marry may drive MSM to have female partners, indicating the potential for bridging HIV transmission. However, these interactions are poorly understood, and measurement of potential risk to MSM and their female partners is inconsistent in most of the South Asian countries, where sex is tabooed, legal system criminalizes homosexuality and is restricted even in programmatic discussions. The study aims to analyze the overlapping male and female partnerships of MSM-SW given the multiplicity of risk for HIV.

Methods: This paper uses data collected as a part of mapping and size estimation of MSM in Nepal, Bhutan, and Bangladesh and for India, the data collected as part of IBBA during 2010 to 16 . Analytical methods range from cross-country comparisons of tangible indicators to application of binary logistic regression.

Results: Bisexuality in the region is rampant as a substantial proportion of MSMs (ranging from $42 \%$ in India to $74 \%$ in Bhutan) who have sex with a male in the last six months also reported to sleeping with a female partner during the same period. MSM age 20-29 years, who are never married and migrants are significantly more likely to have multiple female partners in each of the four countries. Among those who didn't use a condom in the last homosexual encounter, over two-fifths reported condom use in the last sex with a female partner. However, the considerably lower prevalence of condom use, among those having sex with multiple female partners in the last six months in each of the four countries is a marker of the multiplicity of the STIs/HIV risk. Multivariate logistics regression determine that migration is playing an inverse role in determining the relationship with condom use in the last sex with female partner as those MSM who are non-migrants were more likely to use condom as compare to those are migrants across the countries of South Asia

Conclusions: Role of MSM-SW in HIV transmission is a more complex issue than depictions of men as sexual predators and women as uninformed victims. MSM programs should envisage beyond homosexuality and address bisexuality regardless of their sexual identity as threat clouding prevention efforts by increasing the thrust of programs designed for MSMs adopting the network-based approach in the region.
\end{abstract}

\section{Abbreviations: \\ MSM: Men who have sex with men \\ TG: Transgender \\ HIV: Human immunodeficiency virus infection \\ STI: Sexually Transmitted Infection \\ AIDS: Acquired immune deficiency syndrome \\ IBBA: Integrated Behavioral and Biological Assessment}

\section{Introduction}

The term "men who have sex with men" (MSM) denotes all men who have sex with men, regardless of their sexual identity and sexual orientation. In South Asia, there is a high and rising HIV prevalence rate identified among MSM. There are approximately 4-5 million men who have sex with men (MSM) in the region. HIV prevalence rate among
MSM in South Asian countries ranges from 5.2 percent to 28.8 percent. Women account for 37 percent of the total number of people living with HIV and majority of them were infected by their intimate partner [1,2]. However, Men having Sex with Men (MSMs), a recognized core group, are also a powerful driving force [3].

Given the existing societal norms in marriages in the South Asian countries, many MSMs are married and engage in marital sex. It is practiced as a social duty in response to strong social norms and intense familial and community pressure for procreation and as a defense

Correspondence to: Deepanjali Vishwakarma, Doctoral Fellow, International Institute for population Sciences, Mumbai, Maharashtra, India, Email: deepanjali.vishwakarma7@gmail.com

Received: November 29, 2016; Accepted: December 16, 2016; Published: December 22, 2016 
mechanism to avoid stigma and discrimination from homosexuality. Owing to the stigma and discrimination attached to homosexuality, documentation of the nature of homosexual and bisexual behavior is difficult [4]. Stigma and discrimination have been identified as leading obstruction to strong responses to HIV since the inception of the HIV/ AIDS epidemic [5,6]. People who hold stigmatizing and discriminatory attitudes are less likely to have preventive behaviors and more likely to have multiple sex partners, a commercial sex partner, and some other HIV-related high-risk behaviors $[7,8]$.

In the socio-cultural context of South Asia, the issue of male to male sexual behaviors and their impact on the reproductive and sexual health of males and females has profound implications for the effective control and management of STDs and HIV infections in the region. However, the existence of MSMs in South Asia, the extent of male to male sexual behaviors and its impact on the HIV epidemic have been largely ignored [4].

Among bisexual MSMs, sexuality driven risk engender spectrum of vulnerability for both genders. Pressure to marry may drive a greater proportion of MSMs to have female partners, indicating the potential for bridging HIV transmission [9]. However, these interactions are poorly understood, and measurement of potential risk to MSM and their female partner is inconsistent especially in conservative societies like Bhutan, Nepal, India and Bangladesh where sex is tabooed, and homosexuality is restricted even in programmatic discussions.

Such overlapping of homosexual and heterosexual intercourse and sexual risk behaviors among MSM translates into a spectrum of STI/HIV vulnerabilities for both their male as well as female partner's health. These multiple sexual risks engender a variety of repercussions on the wellbeing of both the genders. The majority of the targeted interventions (TIs) and prevention programs principally focus on reducing male-to-male HIV transmissions and reducing risk in homosexual sex. They disregard the risks that the female partners of these MSM face. Under this backdrop, it becomes essential to gain more clarity on the role that MSM/W play in shaping the STI/HIV vulnerability of their female partners. This paper makes an attempt to map the overlapping sexual risks among MSM that elevate the vulnerability of their female partners to STI/HIV.

\section{Data and methods}

Table 1. Percent distribution of MSM by their background characteristics.

\begin{tabular}{|l|c|c|c|c|}
\hline Background & Bhutan & Nepal & India & Bangladesh \\
\hline characteristics & $\mathbf{( 2 0 1 2 - 2 0 1 3 )}$ & $\mathbf{( 2 0 1 0 - 2 0 1 1 )}$ & $\mathbf{( 2 0 0 9 - 2 0 1 0 )}$ & $\mathbf{( 2 0 1 5 - 2 0 1 6 )}$ \\
\hline Age & & & & \\
\hline Below 20 & $6.5(19)$ & $24.9(544)$ & $13.9(603)$ & $9.8(212)$ \\
\hline $20-29$ & $48.5(52.0)$ & $46.1(1006)$ & $52.0(2257)$ & $66.3(1437)$ \\
\hline 30 and above & $45.1(132)$ & $29.0(632)$ & $34.1(1479)$ & $23.9(518)$ \\
\hline Education & & & & \\
\hline Illiterate & $18.8(55)$ & $22.2(484)$ & $14.7(636)$ & $16.5(358)$ \\
\hline Up to 5 years & $9.9(29)$ & $14.3(311)$ & $6.2(269)$ & $28.4(616)$ \\
\hline $6-10$ years & $15.4(45)$ & $25.3(533)$ & $45.7(1982)$ & $43.1(935)$ \\
\hline 10 and above & $56.0(164)$ & $38.2(854)$ & $33.5(1452)$ & $11.9(258)$ \\
\hline Marital status & & & & \\
\hline Ever Married & $65.6(191)$ & $47.1(1028)$ & $31.6(1372)$ & $20.3(439)$ \\
\hline Never married & $34.4(100)$ & $52.9(1154)$ & $68.4(2967)$ & $79.7(1728)$ \\
\hline Migration & & & & \\
\hline Status & & & & \\
\hline Migrants & $90.5(258)$ & $33.0(721)$ & $3.9(168)$ & - \\
\hline Non-Migrants & $9.5(27)$ & $67.0(1461)$ & $96.1(4171)$ & - \\
\hline Total & $\mathbf{1 0 0 . 0 ( 2 9 3 )}$ & $\mathbf{1 0 0 . 0 ( 2 1 8 2 )}$ & $\mathbf{1 0 0 . 0 ( 4 3 3 9 )}$ & $\mathbf{1 0 0 . 0 ( 2 1 6 7 )}$ \\
\hline
\end{tabular}

The study aims to depict the overlapping male and female sharing of MSM-SW in the view of a multiplicity of risk for HIV. Basic data used in this paper has been collected as a part of mapping and size estimation of MSM in Nepal, Bhutan, and Bangladesh during 2010 to 16 and for India, the IBBA data has been used. IBBA is a sexually transmitted and blood-borne infection prevalence Assessment in highrisk population in India. The IBBA is funded by the Bill and Melinda Gates Foundation (BMGF) and was conducted in Avahan project states of Andhra Pradesh, Maharashtra, Tamil Nadu, Karnataka, Manipur, and Nagaland. Analytical methods range from cross-country comparisons of tangible indicators to application of binary logistic regression.

Time location cluster approach was applied for the study. This study used a participatory approach in which the community members took part in the entire process of field work. Involvement of members from MARP community made the process more inclusive, empowering and useful in enhancing the quality of the data. Local and qualified community members from the MARPs were trained to function as field researchers. The data was collected through canvassing structured questionnaire as a part of a behavioural survey with the help of a well-trained team consisting of social scientists, as well as members of the community. To enable maximum reach to the population, social mapping of key populations was done by adopting a "geographical approach" in which "population of the target group," "risk activities" was defined clearly, and then locations, where these activities took place, were identified to capture hidden population. To get a comprehensive picture of vulnerabilities and also understand the core issues that were critical for the groups, a semi-structured survey instrument was used to collect information on the self-reported sexual behaviour and partnership. An oral informed consent was obtained from all the MSM respondents recruited for the survey. The quantitative data collected from the field was cleaned and analyzed using SPSS. The study employs quantitative techniques using standard statistical tools to achieve the study objectives. The major techniques that have been used for analysis of all parameters include frequency distribution, bivariate, and multivariate binary logistic regression.

\section{Results}

\section{Demographic profile}

Based on the demographic and socioeconomic data collected from MSMs, a profile of the South Asian countries namely Nepal, Bhutan, India, and Bangladesh population has been identified. Table 1 describes the profile of the men who have sex with men (MSM) that supports the clearer understanding of high risk and sensitive population. The overall study population consists of 4339 MSMs in India, $2182 \mathrm{MSMs}$ in Nepal, 2167 MSMs in Bangladesh and 293 in Bhutan.

Table 1 reported that most of the MSM belong to the age group of 20-29 years in all four countries of South Asia such as 49 percent, 46 percent, 52 percent and 66 percent in Bhutan, Nepal, India and Bangladesh respectively. It was reported that 23 to 45 percent MSMs belongs to higher age group i.e. 30 and above years. According to the educational attainment, it was observed that more than around onefourth of the MSM were literate in the selected countries of South Asia except for Nepal (around 78 percent). It was reported that about 56 percent of the MSMs in Bhutan have 10 and above years of schooling whereas this proportion is very low in Bangladesh. On the other hand, a considerable proportion of the study population is found illiterate. Marital status of these men portrays that, more than half of the survey population were never married in all countries except Bhutan such as 
Table 2. Sexual history and current profile of MSM.

\begin{tabular}{|c|c|c|c|c|c|c|c|c|c|c|c|c|}
\hline & \multicolumn{3}{|c|}{ Bhutan } & \multicolumn{3}{|c|}{ Nepal } & \multicolumn{3}{|c|}{ India } & \multicolumn{3}{|c|}{ Bangladesh } \\
\hline & \multicolumn{3}{|c|}{ (2012-2013) } & \multicolumn{3}{|c|}{ (2010-2011) } & \multicolumn{3}{|c|}{ (2009-2010) } & \multicolumn{3}{|c|}{ (2015-2016) } \\
\hline & \begin{tabular}{|c|} 
Mean age \\
at first anal \\
sex \\
\end{tabular} & \begin{tabular}{|c|} 
Mean \\
duration of \\
involvement \\
in anal sex \\
(Years)
\end{tabular} & \begin{tabular}{|c|} 
Mean no. \\
of non- \\
commercial \\
male \\
partner \\
during 3 \\
months
\end{tabular} & $\begin{array}{c}\text { Mean age } \\
\text { at first anal } \\
\text { sex }\end{array}$ & $\begin{array}{c}\text { Mean } \\
\text { duration of } \\
\text { involvement } \\
\text { in anal sex } \\
\text { (Years) }\end{array}$ & $\begin{array}{c}\text { Mean no. } \\
\text { of non- } \\
\text { commercial } \\
\text { male } \\
\text { partner } \\
\text { during } 6 \\
\text { months }\end{array}$ & $\begin{array}{l}\text { Mean age } \\
\text { at first anal } \\
\quad \text { sex }\end{array}$ & $\begin{array}{c}\text { Mean } \\
\text { duration of } \\
\text { involvement } \\
\text { in anal sex } \\
\text { (Years) }\end{array}$ & $\begin{array}{c}\text { Mean no. } \\
\text { of non- } \\
\text { commercial } \\
\text { male } \\
\text { partner } \\
\text { during } 3 \\
\text { months }\end{array}$ & $\begin{array}{l}\text { Mean age at first anal } \\
\text { sex }\end{array}$ & $\begin{array}{c}\text { Mean } \\
\text { duration of } \\
\text { involvement } \\
\text { in anal sex } \\
\text { (Years) }\end{array}$ & $\begin{array}{c}\text { Mean no. } \\
\text { of non- } \\
\text { commercial } \\
\text { male } \\
\text { partner } \\
\text { during } 1 \\
\text { months }\end{array}$ \\
\hline \multicolumn{13}{|l|}{ Age } \\
\hline Below 20 & 17.7 & 1.0 & 2.5 & 15.3 & 3.2 & 18.8 & 15.9 & 3.8 & 23.3 & 13.8 & 4.2 & 2.1 \\
\hline $20-29$ & 20.5 & 4.2 & 3.1 & 16.9 & 7.7 & 28.4 & 16.6 & 8.3 & 24.4 & 15.5 & 8.9 & 1.6 \\
\hline 30 and above & 23.7 & 11.8 & 2.6 & 17.5 & 19.3 & 29.9 & 17.7 & 19.3 & 25.3 & 17.0 & 17.2 & 1.8 \\
\hline \multicolumn{13}{|l|}{ Education } \\
\hline Illiterate & 20.1 & 11.0 & 3.2 & 16.0 & 15.4 & 30.9 & 16.9 & 11.4 & 24.1 & 14.8 & 12.4 & 1.7 \\
\hline Up to 5 years & 23.0 & 6.6 & 1.7 & 16.1 & 11.5 & 47.0 & 16.8 & 13.7 & 25.9 & 14.8 & 10.6 & 1.9 \\
\hline 6-10 years & 18.1 & 5.7 & 4.4 & 16.8 & 8.9 & 29.9 & 16.5 & 11.3 & 24.7 & 16.1 & 9.9 & 1.7 \\
\hline 10 and above & 21.2 & 5.2 & 2.7 & 17.2 & 6.9 & 13.8 & 17.0 & 9.9 & 24.1 & 17.5 & 8.7 & 1.5 \\
\hline \multicolumn{13}{|l|}{ Marital status } \\
\hline Ever Married & 23.0 & 8.8 & 2.2 & 17.2 & 14.2 & 29.8 & 18.1 & 15.7 & 25.4 & 17.0 & 14.4 & 1.6 \\
\hline Never married & 19.6 & 4.1 & 3.3 & 16.3 & 6.2 & 23.7 & 16.3 & 9.4 & 24.0 & 15.4 & 9.4 & 1.7 \\
\hline \multicolumn{13}{|l|}{\begin{tabular}{|l|} 
Migration \\
Status
\end{tabular}} \\
\hline Migrants & 21.2 & 6.7 & 3.0 & 17.1 & 9.4 & 29.8 & 16.9 & 11.8 & 25.8 & -- & -- & -- \\
\hline Non-Migrants & 21.6 & 5.3 & 2.0 & 16.5 & 10.2 & 25.0 & 16.8 & 11.4 & 24.2 & -- & -- & -- \\
\hline
\end{tabular}

53 percent, 68 percent, and 80 percent in Nepal, India, and Bangladesh respectively whereas, in Bhutan, more than two-thirds of the MSMs were married. Migratory status of the study population of the South Asian countries reveals that more than 90 percent of the MSMs in Bhutan are migrants whereas in India it was only 4 percent and almost one-third of MSM in Nepal are migrants.

\section{Homosexuality, homosexual behavior and profiling of risky behavior}

Table 2 shows an analysis of initiation of homosexuality and their risky behavior which is elaborated by the distribution of mean age at first anal sex, the mean duration of involvement in anal sex and the mean number of non-commercial partner during the last six months in various background categories. The overall finding of the inception of homosexuality portrays a comparatively early debut in the homosexual act, which shows that the mean age at first anal sex varies from 16 to 21 years across the South Asian countries. The mean age at first anal sex is considerably high according to their educational attainment in Bhutan as compared to India, Nepal, and Bangladesh. The reported mean age at first anal sex among ever married MSMs of Bhutan was 23 years as compared to never married ( 20 years), and it was also high than rest of the other South Asian countries.

The mean duration of involvement in anal sex varies between 7 years to 11 years across the countries. The duration of involvement was high among the older aged MSM in Bhutan (12 years), Bangladesh (17 years), Nepal and India (19 years) as compared to their counterparts. The mean duration of involvement in anal sex was considerably high among all the illiterate MSM of South Asian countries. One of the significant findings of the study reported that the mean duration of involvement in anal sex decreases with the increasing educational attainment by the MSM. Interestingly it was found that the mean duration of involvement in anal sex with male partner among married MSMs is high across all the countries as compared to never married MSMs.

An average number of non-commercial sexual male partner is an indication of the intensity of MSM activity. The mean number of non- commercial partners during the last six months (for Bangladesh last one month) reveals that there are relatively higher number of partners for those who are below age 20 in Bangladesh, 20-29 years age group in Bhutan and 30 years \& above in Nepal and India. The mean number of non-commercial male partner is inversely related to the educational attainment of MSM as it is higher for those who are either illiterate or having up to 5 years of education across all the four countries. In the case of Bhutan and Bangladesh, the average number of non-commercial partner is high among those who are never married, whereas, in India and Nepal it is greater among the ever-married population. The mean number of non-commercial male sexual partner is high among migrants as compared to non-migrants in all the countries except for the Bangladesh.

\section{Dynamics of homosexuality and their risk to STI/HIV}

To get insight into the risky behavior in these homosexual partnerships, the multi-partner behavior of MSM who had sex in the last six months prior to the survey was analyzed. Analysis has also been done to determine the use of condom and lubricant in the last sex to understand the risky sexual behavior. It is evident from the Table 3 that among MSM who reported to have sex with male non-commercial partners in the last six months, 44 percent of them had 1-2 partners in Bhutan, 40 percent in Nepal and 29 percent in India whereas, in Bangladesh 87 percent have 1-2 male partner (In the last one month).

The intensity of homosexuality seems to be higher in India as 42 percent had 6 and above male sexual partners in the last six months prior to the survey. In India, Nepal, and Bhutan, the multi-partner behavior is more pronounced among older MSM as a larger proportion of MSM age 30 years and above reported 6 or more partners in the last six months. In contrast, a relatively higher proportion of younger (age <less than 20 years) MSM in Bangladesh reported having a greater number of sexual partners in the last one month. Multipartner sexual relationship is fluctuating across all the countries irrespective of the increasing educational attainment which shows education is not playing a significant role in decreasing risky sexual behavior. 
Singh SK (2016) Being a homosexual to bisexual: Overlapping sexual risks among men who have sex with men as well as women in South Asian countries

Table 3. Profile of risky behavior in Homosexual relationships among MSM.

\begin{tabular}{|l|l|}
\hline Background characteristics & Number of male sexual partners in the last six month prior
\end{tabular}

\begin{tabular}{|c|c|c|c|}
\hline \multirow[t]{2}{*}{ (1) } & \multicolumn{3}{|c|}{ to the survey } \\
\hline & 1-2 partners & 3-5 partners & $6 \&$ above partner \\
\hline Bhutan(2012-2013) & & & \\
\hline Age & & & \\
\hline
\end{tabular}

$\%$ MSM reporting use of

Condom in the last non-

commercial MSM Activity

$\%$ MSM reporting use of lubricants in the last non-commercial MSM Activity

Age

Below 20

20-29

30 and above

Education

Illiterate

Up to 5 years

6-10 years

10 and above

Marital status

Ever Married

Never married

Migration Status

Migrants

Non-Migrants

Total

Nepal (2010-2011)

Age

Below 20

20-29

30 and above

Education

Illiterate

Up to 5 years

6-10 years

10 and above

Marital status

Ever Married

Never married

Migration Status

Migrants

Non-Migrants

Total

71.4

44.0

28.6

14.3

40.0
28.6

\begin{tabular}{l|l}
42.9 & 57.1
\end{tabular}

\begin{tabular}{l|l}
50.0 & 16.7
\end{tabular}

40.0

42.9

16.7
20.0

47.4

40.7

32.1

40.0

40.0

43.5

4.3

16.0

42.9

\begin{tabular}{l|l}
\hline 4.0 & 16.0 \\
\hline & 42.9
\end{tabular}

(n)

(a)

Age

Below 20

20-29

30 and above

Education

Illiterate

Up to 5 years

6-10 years

10 and above

Marital status

Ever Married

Never married

Migration Status

Migrants

Non-Migrants

Total

Bangladesh (2015-2016)

Age

Below 20

20-29

30 and above

Education

Illiterate

Up to 5 years

6-10 years

10 and above

Marital status

Ever Married

Never married

Migration Status

Migrants

Non-Migrants

Total

India (2009-2010)

21.1

40.7

0.0

33.3

40.0

25.0

31.6

18.5

37.1

25.0

32.6

22.9

23.9

\begin{tabular}{|c|c|}
\hline 100.0 & 28.6 \\
\hline 76.9 & 11.0 \\
\hline
\end{tabular}

85.7

11.0

28.6

\begin{tabular}{l|c}
85.7 & 0.0 \\
\hline
\end{tabular}

\begin{tabular}{c|c}
85.7 & 100.0 \\
80.0 & 16.7
\end{tabular}

80.0

0.0

26.7

\begin{tabular}{l|r}
81.0 & 19.0 \\
84.6 & 18.5
\end{tabular}

\begin{tabular}{l|r}
84.6 & 18.5
\end{tabular}

78.4

100.0

\begin{tabular}{l|r}
78.4 & 25.0 \\
\hline $\mathbf{8 3 . 0}$ & $\mathbf{1 8 . 8}$
\end{tabular}

\begin{tabular}{l|r}
45.0 & 29.3 \\
41.8
\end{tabular}

\begin{tabular}{l|l}
45.0 & 29.3 \\
\hline 41.8 & 27.6 \\
\hline
\end{tabular}

\begin{tabular}{l|l}
33.5 & 28.5
\end{tabular}

25.7

30.6

38.0

\begin{tabular}{|l|l|}
\hline 34.2 & 25.9 \\
\hline 37.4 & 26.5 \\
\hline
\end{tabular}

\begin{tabular}{l|l}
37.4 & 26.5 \\
\hline 40.6 & 30.0
\end{tabular}

\begin{tabular}{l|l}
44.5 & 29.2
\end{tabular}

\begin{tabular}{l|l}
\hline 38.7 & 29.8 \\
\hline 41.5
\end{tabular}

\begin{tabular}{|l|l|}
\hline 38.7 & 29.8 \\
\hline 41.5 & 27.0 \\
\hline
\end{tabular}

\begin{tabular}{l|l}
\hline & \\
\hline 35.4 & 27.8 \\
\hline
\end{tabular}

42.4

40.2

28.5

28.3

39.9

36.2
29.4

26.3

\begin{tabular}{l|l}
\hline 8 & 31.6
\end{tabular}

31.6

36.8

29.1

31.5

\begin{tabular}{|l|l|} 
& \\
\hline 37.0 & 29.3 \\
\hline 24.4 & 26.3
\end{tabular}

\begin{tabular}{l|l}
24.4 & 26.3 \\
\hline 32.2 & 32.7
\end{tabular}

32.7

\begin{tabular}{l|r}
\hline 43.0 & 31.8 \\
\hline 31.6 & 31.6
\end{tabular}

\begin{tabular}{l|l}
43.0 & 31.8 \\
31.6 & 31.6
\end{tabular}

\begin{tabular}{l|l}
\hline 26.2 & 24.7 \\
\hline
\end{tabular}

24.2

24.7
32.3

\begin{tabular}{l|l}
\hline 31.5 & 34.0 \\
\hline
\end{tabular}

27.6

34.0
26.4

\begin{tabular}{l|l}
\hline 0.0 & 42.9 \\
\hline
\end{tabular}

29.2

28.9

28.7

28.9

(last 1 month)

\begin{tabular}{l|l}
\hline 76.7 & 16.7 \\
\hline 89.0. & 10.1
\end{tabular}

89.0

\begin{tabular}{l|l}
83.8 & 14.4
\end{tabular}

\begin{tabular}{l|l}
83.8 & 16.2 \\
\hline
\end{tabular}

\begin{tabular}{l|l}
82.1 & 15.4 \\
\hline 86.1
\end{tabular}

\begin{tabular}{l|l}
86.1 & 12.3
\end{tabular}

\begin{tabular}{l|r}
\hline 92.8 & 5.4
\end{tabular}

\begin{tabular}{l|r}
\hline 89.5 & 9.8 \\
\hline 85.4 &
\end{tabular}

85.4

9.8

86.5

11.8

\begin{tabular}{|l}
\hline 33.7 \\
\hline 49.2 \\
\hline 35.2 \\
\hline 25.2 \\
\hline 36.8 \\
\hline 49.0 \\
\hline 43.4 \\
\hline 34.5 \\
\hline 46.1 \\
\hline \\
\hline 57.1 \\
\hline 42.1 \\
\hline 42.2 \\
\hline \\
\hline 6.7 \\
\hline 0.9 \\
\hline 1.8 \\
\hline 0.0 \\
\hline 2.6 \\
\hline 1.6 \\
\hline 1.8 \\
\hline 0.8 \\
\hline 2.1 \\
\hline- \\
\hline 1.7 \\
\hline
\end{tabular}

79.2

80.0

79.7

\begin{tabular}{l|l}
\hline 76.4 & 73.9
\end{tabular}

\begin{tabular}{|r|r}
76.4 & 73.9 \\
\hline 80.5 & 75.2 \\
\hline
\end{tabular}

\begin{tabular}{l|r}
78.4 & 76.7 \\
\hline 82.2 & 77.8 \\
\hline
\end{tabular}

\begin{tabular}{|r|r}
\hline 82.2 & 77.8
\end{tabular}

\begin{tabular}{r|r}
78.5 & 74.7
\end{tabular}

\begin{tabular}{|l|r}
78.5 & 74.7 \\
\hline 80.8 & 77.6
\end{tabular}

\begin{tabular}{l|l}
80.3 & 78.0
\end{tabular}

\begin{tabular}{|r|r}
\hline 79.4 & 75.5 \\
\hline 79.7 & 76.3
\end{tabular}

\begin{tabular}{r|r}
$\mathbf{7 9 . 7}$ & $\mathbf{7 6 . 3}$ \\
\hline
\end{tabular}


Singh SK (2016) Being a homosexual to bisexual: Overlapping sexual risks among men who have sex with men as well as women in South Asian countries

Table 4. Percent distribution of MSM having sexual relationship with female by relational intensity with other partners and some selected background characteristics.

\begin{tabular}{|c|c|c|c|}
\hline \multirow[t]{2}{*}{ Sexual overlaps } & \multirow[t]{2}{*}{ Ever had sex with Female } & \multirow[t]{2}{*}{ Mean no. female sexual partner } & \multirow{2}{*}{$\begin{array}{c}\text { Ever had sex with Female } \\
\text { OR }(95 \% \text { CI })\end{array}$} \\
\hline & & & \\
\hline \multicolumn{4}{|c|}{ Bhutan(2012-2013) } \\
\hline \multicolumn{4}{|c|}{ Age } \\
\hline Below $20 \AA$ & 66.7 & 4.6 & 1.0 \\
\hline $20-29$ & 92.7 & 4.0 & $4.5(1.13-18.02)$ \\
\hline 30 and above & 96.9 & 3.7 & $10.7 * * *(1.72-66.65))$ \\
\hline \multicolumn{4}{|l|}{ Education } \\
\hline Illiterate ${ }^{\circledR}$ & 87.3 & 3.2 & 1.0 \\
\hline Up to 5 years & 100.0 & 2.2 & $\#$ \\
\hline $6-10$ years & 91.1 & 6.8 & $2.5(0.53-11.65)$ \\
\hline 10 and above & 94.3 & 3.6 & $5.5 * * *(1.59-19.08)$ \\
\hline \multicolumn{4}{|l|}{ Marital status } \\
\hline Married $®$ & 96.8 & 3.8 & 1.0 \\
\hline Never married & 85.4 & 4.0 & $0.3 *(0.10-1.07)$ \\
\hline \multicolumn{4}{|l|}{ Migration Status } \\
\hline Migrants ${ }^{\circledR}$ & 93.3 & 4.0 & 1.0 \\
\hline Non-migrants & 92.3 & 2.7 & $1.1(0.21-5.33)$ \\
\hline Total & 93.0 & 3.7 & \\
\hline \multicolumn{4}{|c|}{ Nepal (2010-2011) } \\
\hline \multicolumn{4}{|c|}{ Age } \\
\hline Below $20 \AA$ & 56.8 & 9.7 & 1.0 \\
\hline $20-29$ & 72.5 & 5.6 & $0.9(0.78-1.27)$ \\
\hline 30 and above & 86.2 & 11.9 & $0.7 *(0.46-1.04)$ \\
\hline \multicolumn{4}{|l|}{ Education } \\
\hline Illiterate & 76.0 & 16.8 & 1.0 \\
\hline Up to 5 years & 73.3 & 10.9 & $1.3(0.85-2.02)$ \\
\hline $6-10$ years & 73.1 & 6.1 & $1.9^{* * *}(1.32-2.78)$ \\
\hline 10 and above & 69.9 & 4.2 & $2.3 * * *(1.64-3.29)$ \\
\hline Marital status & & & \\
\hline Married & 96.9 & 8.7 & 1.0 \\
\hline Never married & 50.9 & 8.4 & $0.02 * * *(0.01-0.03)$ \\
\hline Migration Status & & & \\
\hline Migrants & 66.6 & 9.0 & 1.0 \\
\hline Non-migrants & 75.5 & 8.4 & $1.3^{* *}(1.05-1.68)$ \\
\hline Total & 72.0 & 16.3 & 21.8 \\
\hline India (2009-2010 & & & \\
\hline Age & & & \\
\hline Below $20 \AA$ & 21.9 & 5.3 & 1.0 \\
\hline $20-29$ & 27.4 & 5.6 & $0.5 * * *(0.36-0.60)$ \\
\hline 30 and above & 57.2 & 5.0 & $0.2 * * *(0.15-0.31)$ \\
\hline Education & & & \\
\hline Illiterate $\circledR$ & 51.3 & 6.5 & 1.0 \\
\hline Up to 5 years & 47.2 & 6.6 & $1.0(0.65-1.67)$ \\
\hline $6-10$ years & 35.6 & 4.6 & $0.9(0.71-1.29)$ \\
\hline 10 and above & 30.2 & 5.7 & $0.9(0.62-1.17)$ \\
\hline Marital status & & & \\
\hline Married $®$ & 91.5 & 5.1 & 1.0 \\
\hline Never married & 11.5 & 5.6 & $0.006^{* * *}(0.005-0.009)$ \\
\hline Migration Status & & & \\
\hline Migrants ${ }^{\circledR}$ & 32.7 & 7.6 & 1.0 \\
\hline Non-migrants & 36.9 & 5.3 & $1.8^{* *}(1.03-3.13)$ \\
\hline Total & 36.8 & 5.4 & 24.7 \\
\hline Bangladesh (201 & & & \\
\hline Age & & & \\
\hline Below $20 \AA$ & 17.8 & 1.7 & 1.0 \\
\hline $20-29$ & 32.2 & 1.5 & $1.9^{* *}(1.09-3.23)$ \\
\hline 30 and above & 71.7 & 1.2 & $2.9^{* * *}(1.45-5.79)$ \\
\hline Education & & & \\
\hline Illiterate $\circledR$ & 45.3 & 1.5 & 1.0 \\
\hline Up to 5 years & 44.8 & 1.6 & $1.3(0.74-2.23)$ \\
\hline $6-10$ years & 37.1 & 1.2 & $0.8(0.48-1.37)$ \\
\hline 10 and above & 34.0 & 1.3 & $0.7(0.37-1.24)$ \\
\hline Marital status & & & \\
\hline Married $(\circledR$ & 77.0 & 1.2 & 1.0 \\
\hline Never married & 23.7 & 1.6 & $0.1^{* * *}(0.08-0.19)$ \\
\hline Migration Status & & & \\
\hline Migrants & - & - & - \\
\hline Non-migrants & - & - & - \\
\hline Total & 39.2 & 1.4 & 1.6 \\
\hline
\end{tabular}

(RReference; ${ }^{* * *} \mathrm{p}<0.01,{ }^{* *} \mathrm{p}<0.05,{ }^{*} \mathrm{p}<0.10 ;$ \# low cell frequency 
Analysis of sexual partners by their marital status shows a very distinct pattern among all the South Asian countries. In Nepal, the number of male sexual partner in last six months is around 32 percent with the married MSM whereas, in Bhutan, the percentage of 6 and above male partners among ever-married men is about 32 percent as against 19 percent among never married MSM. On the other hand, in India, the risk behavior among never married MSM was higher (46 percent) as against ever married male (35 percent). The data for risk behavior in Bangladesh was collected for last one month. Therefore, the observed sample size was less. The result shows that 2 percent never of married MSMs had 6 and above male sexual partner in last one month as against 0.8 percent among ever married in Bangladesh. According to their migration status, more than one-third of migrants MSM had 6 or more male sexual partner in the last six months in Nepal whereas, in Bhutan, the proportion was 23 percent. The proportion of migrants MSM having 6 or more partners was higher in India than the other South Asian countries as 57 percent. It was also observed that the proportion of migrants MSM having 3- 5 partners in the last six month prior to survey were showing the distinct variation from country to country such as 37 percent 28 percent and 43 percent in Bhutan, Nepal, and Nepal respectively.

Table 3 also provides the proportion of MSM reporting condom and lubricant used in the last sexual encounter with a non-commercial partner. It was reported that the lower proportion of MSMs used condom in last sex in Bangladesh (58 percent) in comparison to Bhutan ( 83 percent), Nepal ( 80 percent) and India ( 98 percent). The use of condom in the last sex does not vary significantly when analyzed with their different background characteristics. The information on lubricant used in last non-commercial sexual activity was collected only in Bhutan and Nepal. The proportion of MSM used lubricant in the non-commercial sexual activity was 19 percent in Bhutan whereas this proportion was much higher in Nepal (76 percent).

\section{Bisexuality, heterosexual behavior and profiling of risky behaviour}

As many studies concluded that the majority of HIV infections are transmitted through heterosexual route and extent of bisexuality is resulting into multiple dimension of sexual mixing that enhances risky behavior in heterosexual sex. Table 4 depicts that high level of sexual mixing is an important marker of multiplicity of risk as 93 percent of the MSM in Bhutan, 72 percent in Nepal, 37 percent in India and 39 percent in Bangladesh reported ever having sex with the female partners too. Not only bisexuality but the multi-partner behavior among bisexual is also marked, as the mean number of female sexual partner of MSM is very high, i.e., 16 female sexual partners in Nepal, 5 partners in India, 4 partners in Bhutan and 2 female partners in Bangladesh in last six months.

Additionally, extending the results on bisexuality according to the background characteristics, it was reported that the proportion of MSM who ever had sex with a woman was higher among 30 and above age and have at least five years of education across all these countries. According to their marital status, in India, the percentage of MSMs who reported to ever had sex with women is higher among those who are never married whereas the situation seems to be contrasted in all other countries. In all the South Asian countries included in the study, migrant MSMs are more likely to have multiple female sexual partners as compared to non-migrant in the last six months.

Adjusted effects of various predictors included in the logistic regression model to analyze the major covariates of bisexuality among
MSM portrays that those who are 10 or more years educated were 5.5 [CI (1.59-19.08), $\mathrm{p}<0.01$ ] times more likely to have sex with a woman in Bhutan and 2.3[CI (1.64-3.29), $\mathrm{p}<0.01$ ] times more likely to have sex with a woman in Nepal. When migration status was considered then, the result revealed that those MSM who are native were 1.3 [CI (1.051.68), $\mathrm{p}<0.05$ ] times more likely in Nepal, 1.8 [CI (1.03-3.13), $\mathrm{p}<0.05$ ] times more likely in India to have sex with female partners.

\section{Dynamics of heterosexuality and risky sexual behavior influencing women's vulnerability to STI/HIV}

The pattern of heterosexuality was analyzed concerning a number of female sexual partners in the last six months prior to the survey and the condom use reported in the last sex with female partner along with some background characteristics. It is evident from Table 5 that among those who reported ever having sex with a female partner, 75 percent MSM have less than two female partners in Nepal and Bangladesh whereas in Bhutan and India the percentage are 35 and 48 respectively. In case of Nepal, Bhutan and Bangladesh, the proportion of MSM those who have had 4 \& above female partners in the last six months prior to the survey were considerably high in below 20 years of age group and those who are never married as compared to their counter parts. In India, the situation is contrast to other countries, here the extent of bisexuality is going with older and married MSMs in term of 4 and above female sexual partner in the last six months prior to the survey.

The proportion of literate MSMs those have 4 or more female sexual partners in the last six months prior to the study were considerably high in Nepal and India, and educational status is found playing a negative role in increasing the risk of multiple sexual partners relationship. According to their migratory status in India interestingly it is found that all migrant MSMs had less than 2 female sexual partners.

Further analysis of condom use in the last sex with female partner portrays that only 64 percent of MSMs in Bhutan used condom with female partner in the last sexual act, while this percentage in Nepal, India and Bangladesh was low as 54 percent, 30 percent, and 36 percent respectively. It was reported that unmarried MSM was more frequent to use condom in last sexual act with female partners. Result shows that 79 percent unmarried MSM as against 58 percent Married MSM in Bhutan, 72 percent Unmarried as against 44 percent married MSMs in Nepal, 80 percent unmarried MSMs as against 17 percent married MSMs in India and 58 percent unmarried MSMs as against 19 percent married in Bangladesh reported to use condom in the last sex with female partners. These results clear the picture that women are more prone to risk of STI/HIV by their male sexual partners. Interestingly there is inverse relationship between condom use in the last sex with female partner and their current age i.e., the percentage of MSM using condom was declining from younger (age below 20) to older age group (30 and above) of MSMs such as 75 to 56 percent in Bhutan, 71 to 43 percent in Nepal, 82 to 17 percent in India and 53 to 19 percent condom use declined in Bangladesh. The interface of age and marital status of MSM provides an important marker for multiplicity of risk for STI/HIV. In the context of migration the condom use in the last sex with female partners among migrants MSM is found to be low as compared to non-migrants in Nepal and India.

In the study, multivariate binary logistics regression was used to determine the factor associated with condom used in last sex with female partners. Adjusted effects of condom used in last sex with female partners show that never married MSM were more likely to used condom in last sex with female partners in the selected south Asian countries except India such as 2.2[CI (1.08-4.44), $\mathrm{p}<0.05]$ times 
Singh SK (2016) Being a homosexual to bisexual: Overlapping sexual risks among men who have sex with men as well as women in South Asian countries

Table 5. Profile of risky behaviour in Heterosexual relationships among MSM.

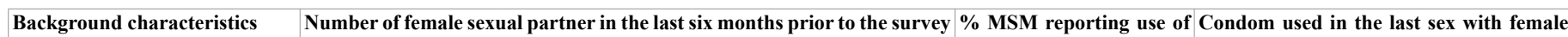
Condom in the last sex partner
Con

\begin{tabular}{|c|c|c|c|c|c|}
\hline & $<2$ partner & 2-3 partner & 4 \&above partner & with female partner & OR $(95 \%$ CI) \\
\hline \multicolumn{6}{|c|}{ Bhutan(2012-2013) } \\
\hline \multicolumn{6}{|l|}{ Age } \\
\hline Below 20 ® & 16.7 & 33.3 & 50.0 & 75.0 & 1.0 \\
\hline $20-29$ & 41.4 & 35.2 & 41.4 & 70.9 & $1.2(0.28-5.32)$ \\
\hline 30 and above & 49.2 & 25.4 & 25.4 & 56.3 & $1.1(0.23-4.90)$ \\
\hline \multicolumn{6}{|l|}{ Education } \\
\hline Illiterate $^{\circledR}$ & 53.1 & 20.4 & 26.5 & 51.0 & 1.0 \\
\hline Up to 5 years & 46.4 & 32.1 & 21.4 & 50.0 & $0.9(0.38-2.54)$ \\
\hline $6-10$ years & 29.3 & 26.8 & 43.9 & 65.9 & $1.7(0.67-4.04)$ \\
\hline 10 and above & 29.1 & 34.5 & 36.5 & 70.7 & $1.8(0.86-3.60)$ \\
\hline \multicolumn{6}{|l|}{ Marital status } \\
\hline Married ${ }^{\circledR}$ & 43.4 & 25.8 & 30.8 & 57.5 & 1.0 \\
\hline Never married & 18.3 & 39.0 & 42.7 & 79.3 & $2.2 * *(1.08-4.44)$ \\
\hline \multicolumn{6}{|c|}{ Migration Status } \\
\hline Migrants $^{\circledR}$ & 35.2 & 30.1 & 34.7 & 62.7 & 1.0 \\
\hline Non-migrants & 29.2 & 37.5 & 33.3 & 83.3 & $2.7 *(0.87-8.08)$ \\
\hline Total & 35.3 & 30.5 & 34.2 & 64.2 & 0.83 \\
\hline \multicolumn{6}{|c|}{ Nepal (2010-2011) } \\
\hline \multicolumn{6}{|l|}{ Age } \\
\hline Below 20® & 62.8 & 14.2 & 23.0 & 70.7 & 1.0 \\
\hline $20-29$ & 75.0 & 10.7 & 14.3 & 55.5 & $0.8(0.59-1.12)$ \\
\hline 30 and above & 81.7 & 7.7 & 10.6 & 43.1 & $0.8(0.54-1.14)$ \\
\hline \multicolumn{6}{|l|}{ Education } \\
\hline Illiterate $^{\circledR}$ & 76.6 & 9.8 & 13.6 & 38.3 & 1.0 \\
\hline Up to 5 years ${ }^{\circledR}$ & 74.6 & 12.7 & 12.7 & 46.7 & $1.3(0.91-1.82)$ \\
\hline $6-10$ years & 74.3 & 9.4 & 16.3 & 56.5 & $1.7^{* * *}(1.26-2.32)$ \\
\hline 10 and above & 74.4 & 10.5 & 15.1 & 65.6 & $2.2^{* * *}(1.63-2.96)$ \\
\hline \multicolumn{6}{|l|}{ Marital status } \\
\hline Married $^{\circledR}$ & 80.0 & 8.7 & 11.2 & 44.2 & 1.0 \\
\hline Never married & 66.3 & 13.1 & 20.6 & 71.5 & $2.4^{* * *}(1.82-3.16)$ \\
\hline \multicolumn{6}{|c|}{ Migration Status } \\
\hline Migrants $^{\left({ }^{\circledR}\right.}$ & 75.6 & 8.5 & 15.8 & 52.4 & 1.0 \\
\hline Non-migrants & 74.6 & 11.2 & 14.2 & 55.0 & $1.3^{* *}(1.05-1.67)$ \\
\hline Total & 74.9 & 10.4 & 14.7 & 54.2 & 0.54 \\
\hline \multicolumn{6}{|c|}{ India (2009-2010) } \\
\hline \multicolumn{6}{|l|}{ Age } \\
\hline Below $20^{\circledR}$ & 60.3 & 10.3 & 29.4 & 81.7 & 1.0 \\
\hline $20-29$ & 43.9 & 13.3 & 42.9 & 36.9 & $0.5^{* *}(0.29-0.88)$ \\
\hline 30 and above & 39.0 & 14.6 & 46.3 & 16.8 & $0.4^{* * *}(0.24-0.81)$ \\
\hline Education & & & & & \\
\hline Illiterate $^{\circledR}$ & 56.3 & 3.1 & 40.6 & 15.8 & 1.0 \\
\hline Up to 5 years & 31.6 & 21.1 & 47.4 & 26.8 & $1.9^{* *}(1.05-3.25)$ \\
\hline $6-10$ years & 51.6 & 14.0 & 34.4 & 31.1 & $1.7 * * *(1.13-2.47)$ \\
\hline 10 and above & 44.4 & 12.7 & 42.9 & 39.7 & $2.2^{* * *}(1.45-3.33)$ \\
\hline Marital status & & & & & \\
\hline Married $^{\circledR}$ & 47.9 & 11.3 & 40.8 & 16.6 & 1.0 \\
\hline Never married & 48.5 & 13.2 & 38.2 & 79.8 & $13.9(9.58-20.29)$ \\
\hline Migration Stat & & & & & \\
\hline Migrants $^{\sqrt{(\mathbb{R}}}$ & 100.0 & 0.0 & 0.0 & 10.0 & 1.0 \\
\hline Non-migrants & 48.1 & 12.6 & 39.3 & 30.6 & $3.7^{* *}(1.27-10.50)$ \\
\hline Total & 48.3 & 12.6 & 39.1 & 30.0 & 1.02 \\
\hline Banglades & & & & & \\
\hline Age & & & & & \\
\hline Below $20^{\circledR}$ & 57.9 & 36.8 & 5.3 & 52.6 & 1.0 \\
\hline $20-29$ & 68.6 & 27.2 & 4.2 & 47.6 & $1.1(0.41-3.02)$ \\
\hline 30 and above & 85.2 & 14.1 & 0.7 & 19.0 & $0.7(0.22-2.18)$ \\
\hline Education & & & & & \\
\hline Illiterate $^{\circledR}$ & 65.1 & 32.6 & 2.3 & 44.2 & 1.0 \\
\hline Up to 5 years & 64.9 & 28.7 & 6.4 & 35.1 & $0.5 *(0.22-1.12)$ \\
\hline $6-10$ years & 80.6 & 18.1 & 1.3 & 39.4 & $0.8(0.37-1.65)$ \\
\hline 10 and above & 81.8 & 16.4 & 1.8 & 23.6 & $0.4 *(0.16-1.09)$ \\
\hline Marital status & & & & & \\
\hline Married $^{\circledR}$ & 84.6 & 14.4 & 1.0 & 19.4 & 1.0 \\
\hline Never married & 61.6 & 33.1 & 5.3 & 58.9 & $4.8^{* * *}(2.65-8.74)$ \\
\hline Migration Stat & & & & & \\
\hline Migrants $^{\circledR}$ & - & - & - & - & - \\
\hline Non-migrants & - & - & - & - & - \\
\hline Total & 74.7 & 22.4 & 2.8 & 36.4 & 0.44 \\
\hline
\end{tabular}

(囚) Reference; $* * * \mathrm{p}<0.01, * * \mathrm{p}<0.05, * \mathrm{p}<0.10$ 
in Bhutan, 2.4 [CI (1.82-3.16), $\mathrm{p}<0.01]$ times in Nepal and 4.8[ CI $(2.65$ 8.74), $\mathrm{p}<0.01]$ times in Bangladesh. Adjusted effects of these predictors on the condom use with female sexual partners portray a positive relation between MSMs education and their protected sexual behavior in India and Nepal. The results present that educated MSMs were more likely to use condom in the last sex with their female partners as 2.2 [CI (1.45-3.33), $\mathrm{p}<0.01]$ times in India and 2.2 [CI (1.63-2.96), $\mathrm{p}<0.01]$ times in Nepal. The results show that migration is playing an inverse role in determining the relationship between condom use in the last sex with female partner as those MSM who are non-migrants were more likely to use condom as compared to those are migrants across the countries of South Asia such as 2.7 [CI (1.08-4.44), p $<0.10$ ] in Bhutan, 1.3 [CI (1.05-1.67), $\mathrm{p}<0.05$ ] in Nepal and 3.7 [CI (1.27-10.50), $\mathrm{p}<0.05$ ] were more probable to use condom in lasts sex with female partners. It means that migrants MSM were more likely to not used condom with female partners.

\section{Discussion and conclusions}

The results of this paper highlight that overlapping sexual behavior creates an unbridled sexual risk that makes it challenging for the programme personnel as well as for the public health practitioners. These findings are similar to the finding of the other studies $[9,10]$. The context and environment in which Bisexuality exists in South Asia, envisage sexual risks as it involves the sexual activities with men as well as women, which are highly stigmatized and hence hidden in the society. The fact that involvement of married MSMs in bisexual activities are more may be because of social pressure that leads MSM to marry and have children despite their sexual preference for men. A substantial proportion of married MSMs reported having sex with 6 \& above male partners across all the four countries except in Bangladesh, where average number of male sexual partners is relatively lower in the last 30 days prior to the survey. These findings of the study clearly reveal that the risk of bisexual behavior among ever-married men not only creates a pathway for STIs among themselves but even among their wives back home. A substantial proportion of MSM reporting being sexually active with females, indicates the widespread bisexuality among MSM in South Asia. The literature suggests that in Bangladesh, some married men who have sex with men considered that continuing to have relations with men was better than having sexual relations with women other than wives. They believe that the concept of true love with one wife could not be shared with other women [11] rather an intercourse with men does not affect the love towards their wives. Those MSMs who are having higher number of partners, may be non-commercial partner or commercial partners or the mix of both, can be an issue requiring immediate attention of programmes and interventions to address the multiplicity of risk. A study by Campbell determines that women are at increased risk because the efficiency of male to female transmission is greater than female to male [12].

Practicing of safe sex is not uniform and infrequent in homosexual as well as heterosexual encounters across the South Asian countries. More than two- thirds of MSM reported to use condom in their last MSM activity, but the situation is different in case of sex with female partners. A considerably lower prevalence of condom use with female partners as compared to use with male partners opens a wide window of increasing risk and vulnerability of their female partners. According to report of HIV/AIDS in South East Asia, the condom use at last sexual encounter and consistent condom use is reaching high level among sex workers; however, men who have sex with men, have low rates of condom use [1].
Our study portrays that married MSM are less likely to use safe sexual practices with their female partners, this creates a pathway to STIs/HIV among women. Prevalence of low condom use among married MSMs, which is also declining with age has a potential to increase HIV vulnerability among their female partners. Which is primarily due to lack of perceived need to use safe sex within wedlock, which may be a symbol of lacking faith in each other. This is a negative connotation emerging primarily in case of MSM, especially among bisexuals and hence, there is a need to enhance women's awareness to STI/HIV vulnerabilities due to their partner's behavior. A major assumption of most HIV research and interventions is that the women partners of MSM are unaware of the high-risk behaviors of their husbands/partners, which are primarily a result of social and cultural restrictions and the retroaction attracted by same-sex behavior in society [9].

Results of the paper have also highlighted that migration of MSM is a significant predictor of women's vulnerability to HIV/AIDS in the region. In India, Nepal and Bhutan migrant MSM have significantly larger number of female sexual partners than their non-migrant counterparts. This may be resulted due to lack of immediate moral pressure and social control among migrant MSM providing them much more conducive environment to indulge in bisexuality with range of partners. Migrant MSM are less empowered at the place of destination in comparison to their non-migrant counterpart, which may be reason behind low prevalence of condom use in case of sex with females. A similar finding was observed in a study in China, where major reasons for such a finding could be that migrants MSM, who had sex with females, may have more varied sexual behaviors with a wider range of sexual partners among both males and females [13]. Further, a cross-sectional study among migrant MSM in Beijing revealed that MSM who were involved in bisexual behavior had a higher proportion of unsafe sex with stable female partners and were less likely to take a part in preventive behaviors [14]. Therefore, any programme and intervention to address STI/HIV vulnerability among MSM, who are bisexual, there should a strong component of their capacity building to adopt safe sexual practices in one hand and enhancing women's empowerment to assess their partner's background and behavior to reduce their own vulnerability on the other.

\section{Recommendations}

Programmes and Interventions designed to address STI/HIV risk among MSM in the region should focus on enhancing access and utilization of condom and lubricant through scaling up to condom depots at various strategic locations adopting innovation approaches.

In view of a large majority of MSM in the region being bisexual, researchers as well as programmer personnel need attention to envisage beyond homosexuality and bisexuality, rather focus on female partners of MSMs to address their STI/HIV vulnerability through consistent condom use.

\section{Limitation of the study}

The study is cross-sectional and does not examine reported Behaviour over time. The study uses a wide window of time to define bisexual Behaviour that may have a bearing on the extent of bisexuality and it contribution in epidemic.

\section{References}

1. HIV/AIDS (2011) in South East Asia region progress report.

2. HIV/AIDS (2010) among men who have sex with men and transgender populations 
in South-East Asia: The current situation and national responses. World Health Organization, Regional Office for South-East Asia, 2010.

3. NACO UNGASS (2010) Country Progress Report-India.

4. Situational Assessments in Sexual Health Among Males Who Have Sex With Males And Their Sexual Partners in South Asia, final report NAZ Foundation International, FHI.

5. Carr D, Eckhaus T, Brady L, Watts C, Zimmerman C, et al (2010) Scaling up the response to HIV stigma and discrimination: International Center for Research on Women and London School of Hygiene \& Tropical Medicine.

6. Grossman AH (1991) Gay men and HIV/AIDS: understanding the double stigma. $J$ Assoc Nurses AIDS Care 2: 28-32. [Crossref]

7. Genberg BL, Hlavka Z, Konda KA, Maman S, Chariyalertsak S, et al. (1982) A comparison of HIV/AIDS-related stigma in four countries: negative attitudes and perceived acts of discrimination towards people living with HIV/AIDS. Social Science \& Medicine 68: 2279-2287.

8. Li X, Lu H, Ma X, Sun Y, He X, et al. (2012) HIV/AIDS-related stigmatizing and discriminatory attitudes and recent HIV testing among men who have sex with men in Beijing. AIDS Behav 16: 499-507. [Crossref]

9. Singh SK, Sharma N, Tshering N, Siddhanta A (2015) Living a Dual Life: Multiplicity of Sexual Risks among Men who have Sex with Men 'and' Women in Bhutan. J Aids HivInfec 1: 203.
10. Singh SK, Sharma N, Malviya A, Mondal S (2014) Down-Low: Overlapping Sexual Risks of Bisexual MSM Influencing Women's Vulnerability to STI/HIV in Nepal Sexuality \& Culture 18: 331-345.

11. Khan SI, Hudson-Rodd N, Saggers S, Bhuiya A (2005) Men who have sex with men's sexual relations with women in Bangladesh. Cult Health Sex 7: 159-169. [Crossref]

12. Campbell CA (1999) Women, families and HIV/AIDS: A Sociological Perspective on the Epidemic in America. Cambridge University Press.

13. Mao H, Ma W, Lu H, Wang L, Zheng H, et al. (2014) High incidence of HIV and syphilis among migrant men who have sex with men in Beijing, China: a prospective cohort study. BMJ Open 4: e005351. [Crossref]

14. Peng Y, Chang W, Zhou H, Hu H, Liang W (2010) Factors associated with healthseeking behavior among migrant workers in Beijing, China. BMC Health Services Research 10: 1 .

15. Cáceres CF, Konda K, Segura ER, Lyerla R (2008) Epidemiology of male same-sex behaviour and associated sexual health indicators in low-and middle-income countries: 2003-2007 estimates. Sexually Transmitted Infections 84: i49-i56.

16. Indian Council of Medical Research and FHI 360 (2011) National summary reportIndia, Integrated behavioural and biological assessment (IBBA), Round 2 (2009-2010). New Delhi: Indian Council of Medical Research and FHI 360

17. NACO Annual Report 2012.

Copyright: (C2016 Singh SK. This is an open-access article distributed under the terms of the Creative Commons Attribution License, which permits unrestricted use, distribution, and reproduction in any medium, provided the original author and source are credited. 